\title{
New Improved Thermoluminescence Magnesium Silicate Material for Clinical Dosimetry
}

Mohamed Ragab Abass ( $\triangle$ mohamed.ragab2014300@yahoo.com )

Egyptian Atomic Energy Authority https://orcid.org/0000-0002-1766-0449

Hassan M. Diab

National Institute of Standards, Egypt

Mamdouh M. Abou-Mesalam

Egyptian Atomic Energy Authority

\section{Research Article}

Keywords: Thermoluminescence, Magnesium silicate, Dosimetry, Glow curve

Posted Date: March 1st, 2021

DOI: https://doi.org/10.21203/rs.3.rs-274318/v1

License: (1) This work is licensed under a Creative Commons Attribution 4.0 International License. Read Full License

Version of Record: A version of this preprint was published at Silicon on March 11th, 2021. See the published version at https://doi.org/10.1007/s12633-021-01049-9. 


\begin{tabular}{|c|c|c|c|}
\hline Name & E-mail & Affiliation & Orcid \\
\hline $\begin{array}{c}\text { Mohamed R. } \\
\text { Abass }\end{array}$ & $\underline{\text { mohamed.ragab2014300@ }}$ & $\begin{array}{c}\text { Egyptian Atomic } \\
\text { Energy Authority }\end{array}$ & $\begin{array}{c}\text { 0000-0002- } \\
1766-0449\end{array}$ \\
\hline Hassan M. & $\underline{\text { hdiab2003200327@yahoo. }}$ & $\begin{array}{c}\text { National Institute of } \\
\text { Standards, Egypt }\end{array}$ & \\
Diab & $\underline{\text { com }}$ & Egyptian Atomic & \\
Mamdouh M. & $\underline{\text { mabumesalam@yahoo.co }}$ & Energy Authority & \\
Mesalam & $\underline{m}$ & & \\
\hline
\end{tabular}

*Corresponding Author: Mohamed R. Abass

E-mail: mohamed.ragab2014300@yahoo.com

Mobile Number: 00201153334821

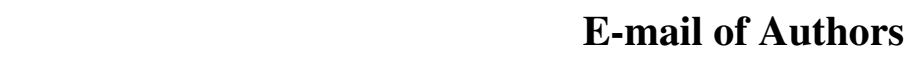




\section{Abstract}

Magnesium silicate has been prepared by a precipitation technique. This composite structure was proven by different tools, XRD, TGA\&DTA, FTIR, and XRF.

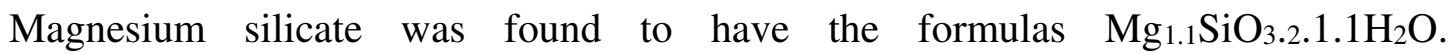
Thermoluminescence (TL) dosimetric properties like (linearity, fading, energy independence) of magnesium silicate in the shape of $\mathrm{MgSiO}_{3}$ have been estimated. A strong TL dosimetry peak associated with gamma radiation arises from ${ }^{137} \mathrm{Cs}$ was developed. Different doses from gamma radiation were measured by thermoluminescence (TL) detection technique for magnesium silicate glasses in unique magnesium elements concentration to assess its dosimetric properties. A single strong peak of about $230{ }^{\circ} \mathrm{C}$ arises for all irradiated samples. Total integral values of TL output and TL of the principal peak values showing a linear behavior start with 0.5 Gray up to 2 Gray dose range. Correlation of magnesium silicate TL response and different doses showed dose-response improvement concerning low doses linear relationship.

Keywords: Thermoluminescence, Magnesium silicate, Dosimetry; Glow curve

\section{Introduction:}

Inorganic substances of an ion-exchange type have recently played a great role, originally focused on their thermal and radiation resistance besides their chemical hazards [1-3]. Uses of thermoluminescence (TL) phenomenon for suitability testing of glasses being an interesting subject in recent years through radiation-induced defect centers investigations for more technical applications in photonics [4-9]. Thermoluminescence behaviors of $\mathrm{Sr}_{3} \mathrm{MgSi}_{2} \mathrm{O}_{8}$ phosphor doped with $\mathrm{Dy}^{3+}$ were studied by [10]. Also, Chen's method has been utilized for determining the kinetic measurable factors for glow curve deconvolution. Recently, investigation of borosilicate glass glow curves which has a composition (60-x) $\mathrm{B}_{2} \mathrm{O}_{3}-20 \mathrm{SiO}_{2}-10 \mathrm{Na}_{2} \mathrm{O}-10 \mathrm{MgO}-\mathrm{xDy}_{2} \mathrm{O}_{3}$ doped with rare earth after different dose irradiated with high doses of gamma radiation achieved. Samples doped with $0.6 \% \mathrm{~mol}$ $\mathrm{Dy}^{3+}$ showed appropriateness for dosimetric utilizations because of their good 
47 thermoluminescence dose sensitivity and response [11]. Furthermore, TL glow curves

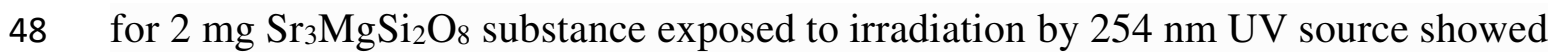
a resolute single peak around $123{ }^{\circ} \mathrm{C}$. A glow curve deconvolution technique was used for analyzed acquired glow curves [12]. Moreover, magnesium orthosilicate intensity of TL glows curves showed a good dose-response linear relationship extended to $20 \mathrm{~Gy}$. To a certain degree, TL features of this phosphor are conditional beside $\mathrm{Mg}_{2} \mathrm{SiO}_{4}$ is suggested to consider as a suitable substance for dosimetry [13]. Also, the photon shielding properties of a glassy system composed of $20 \mathrm{Li}_{2} \mathrm{O}-(70-\mathrm{x}) \mathrm{B}_{2} \mathrm{O}_{3}-$ $10 \mathrm{MgO}-\mathrm{xTm}_{2} \mathrm{O}_{3}$ doped with different $\mathrm{Tm}_{2} \mathrm{O}_{3}$ oxides (where $0 \leq \mathrm{x} \leq 1$ ) were investigated utilizing the advanced program (XCOM). When the $\mathrm{Tm}_{2} \mathrm{O}_{3}$ concentration rise, the mass attenuation coefficients also increased. The variation of

$\mathrm{Tm}_{2} \mathrm{O}_{3}$ concentration affecting the good properties of LMB glasses. It appeared that the glass compositions recommended for solid-state lasers usage [14]. For new sets telluroborate glasses doped of $\mathrm{Sm}^{3+}$ with varying $\mathrm{TeO}_{2}$ content, gamma shielding properties were testing utilizing MCNPX code from energy range from 0.356up to 1.33 MeV. when the $\mathrm{TeO}_{2}$ content changes from 0 up to $40 \%$ mol for all glasses, the calculated mass attenuation coefficient showed an increasing behavior principally at an energy value $0.356 \mathrm{MeV}$, 4TBS glass material displayed the lowest value of half-value layer. The study assures that the alteration of $\mathrm{B}_{2} \mathrm{O}_{3}$ by $\mathrm{TeO}_{2}$ supports the capability of the prepared glassy materials to minimize the gamma photons [15]. Furthermore, TL dosimetric properties for rare-earth-doped tellurite form glasses were examined [13]. Thermoluminescence kinetic parameters examination were used also for glasses of Binary lead silicate type [14], In recent work, prepared magnesium silicate glasses glow curves were testing for dosimetry considering glass structure correlating with different dosimetric properties.

\section{Experimental Work:}

74 Magnesium silicate was fabricated as reported [18], by additional dropwise of $\mathrm{Na}_{2} \mathrm{SiO}_{3}$ to $\mathrm{MgCl}_{2} \cdot 6 \mathrm{H}_{2} \mathrm{O}$ equimolar solutions $(0.5 \mathrm{M})$, which have a volumetric ratio of $\mathrm{Mg} / \mathrm{Si}$

$76=1.5$ at constant agitation at $25 \pm 1{ }^{\circ} \mathrm{C}$. When the addition was finished, that diluted $\mathrm{NH}_{3}$ 
was added until a precipitate was formed, and instead, the reaction mixture was kept undisturbed overnight. With $0.1 \mathrm{M} \mathrm{HNO}_{3}$, a precipitate was washed to remove $\mathrm{Cl}^{-}$and impurities. To kill $\mathrm{NO}_{3}{ }^{-}$a precipitate was cleaned with distilled $\mathrm{H}_{2} \mathrm{O}$. It was soaked several times with $\mathrm{H}_{2} \mathrm{O}$ distilled [18]. Magnesium silicate was dried and ground in a powder form and mixed to a ratio of 1:5 with $\mathrm{KBr}$, then pressed to the IR analysis. FTIR was performed on a computerized spectrophotometer ranges from 4000 up to 400 $\mathrm{cm}^{-1}, \mathrm{KBr}$ discussing the Genesis-IIFT-IR spectrometer. The Philips series X-ray spectrometer-2400 was used to evaluate the stoichiometry of the components in magnesium silicate. The prepared composite was analyzed by XRD using Shimadzu XD-D1. Measurements were done with a speed of $2 \% \min$ in $2 \theta$ ranges from 4 to 90 . Composite fabricated $(20 \mathrm{mg})$ were analyzed for DTA \&TGA with a Shimadzu DTG$60 \mathrm{H}$. Harshaw 4500 TLD reader within a planchet heating pathway used for measuring thermoluminescence response. The glass being closed to a stainless-steel crucible for the heating process; a thermocouple closely connected to the sample holder. After irradiation, heating of the sample achieved by a steady rate equal to $1.5^{\circ} \mathrm{Cs}^{-1}$ extends from $50{ }^{\circ} \mathrm{C}$ up to $400{ }^{\circ} \mathrm{C}$. This method assures set sample doses to zero and subsequently no need for more annealing steps. TL dose-response within dose range starts from $50{ }^{\circ} \mathrm{C}$ up to $400{ }^{\circ} \mathrm{C}$ sample doses expressed by an integral value. ${ }^{137} \mathrm{Cs}$ standards source located at the laboratory of ionizing radiation metrology. National Institute of standards was used, its half-life of 30.17 years. The utilized source was manufactured in Canada with a $23 \mathrm{rad} / \mathrm{min}$ at a distance of $30 \mathrm{~cm}$ on work time. The 2570 farmer-type dosimeter, made in the U.K. by accompany of Nuclear Enterprises Ltd. attached to an ionization chamber with serial number 2571 which is sensitive to gamma rays under the ideal condition of temperature and pressure to observe the dose rate of ${ }^{137} \mathrm{Cs}$ source. The dosimetric properties were achieved with gamma photons from ${ }^{137} \mathrm{Cs}$ source. The dose was computed by the IAEA code of practice with a $2.5 \%$ accuracy value. Every TL- measurement carried out was repeated three times with a net standard deviation equal to $\pm 2 \%$. The average reproducibility for glasses is 0.82 $\%$ which means (1 standard deviation), evaluated by 4500 planchet heating reader, manual type. If the dosimetry process based on accuracy and good repeatability reading 
values are required, it must be careful about the distribution of glasses powder on sample holder at the manual planchet reading mode.

\section{Results and Discussion:}

As already stated in the experimental section, magnesium silicate was fabricated and has a hard granulating in nature with white color. Magnesium silicate formation mechanism (scheme 1), was obtained by replacement of $2 \mathrm{Na}^{+}$by $\mathrm{Mg}^{2+}$ and $2 \mathrm{NaCl}$ molecules were withdrawn.

Magnesium silicate IR spectrum (Figure $1 \&$ Table 1). This Figure displays six characteristic bands. The first vibration of $\mathrm{H}_{2} \mathrm{O}$ and $\mathrm{OH}$ absorbed in the composite appeared at 3150-3670 $\mathrm{cm}^{-1}$ [1]. Owing to a bending vibration for $\mathrm{H}_{2} \mathrm{O}$ in magnesium silicate, a high absorption band showed at $1652 \mathrm{~cm}^{-1}$ [1]. $\mathrm{Mg}-\mathrm{O}$ resulted in a band of 1000 to $1100 \mathrm{~cm}^{-1}[1,19]$. $\mathrm{Mg}-\mathrm{OH}$ deformation vibration resulted in a band at $903 \mathrm{~cm}^{-}$ 1 [20]. Mg-O-Si \& Si-O-Si bending vibrations are connected to two $640 \& 470 \mathrm{~cm}-1$, respectively [21].

XRD for magnesium silicate (Figure 2), reveals that a prepared composite has a crystalline structure. These results were consistent with XRD data from composites operated at different heating temperatures [1,22].

TGA \& DTA chart for magnesium silicate heated at a rate of $10{ }^{\circ} \mathrm{C} / \mathrm{min}$ (Figure 3), through a three-step procedure. A first-stage $\left(43-192{ }^{\circ} \mathrm{C}\right)$ may be due to free water loss $[1,23]$, a weight drop in this heating area is $(8.2 \%)$. A second-stage $\left(192-283{ }^{\circ} \mathrm{C}\right)$ resulted from a break down for residual $\mathrm{OH} \&$ unbonded oxygen condensation [24], a weight drop in this heating area is $(4.45 \%)$. A third-stage $\left(283-800{ }^{\circ} \mathrm{C}\right)$ may be attributed to chemical bond water lost [1], a weight drop in this heating area is (12.8 $\%)$. DTA shows that 2 endothermic peaks about $\left(128 \& 501{ }^{\circ} \mathrm{C}\right)$ could be attributed to free water \& chemical bond water loss, respectively. A single exothermic peak arises at $\left(257{ }^{\circ} \mathrm{C}\right)$ explained by a release of residual $\mathrm{OH}$ decay \& unbonded oxygen condensation. From TGA data (Figure 3), a weight loss for composite prepared is 
extended to $700{ }^{\circ} \mathrm{C}$, and no weight drop happened within a range from 700 up to -800 ${ }^{\circ} \mathrm{C}$. This enhancing the fact that composite prepared has much more thermal stability than other materials. The weight drop for magnesium silicate with the heating temperature that a (33.4\%) weight drop obtained if a substance exposed to calcination process about $800^{\circ} \mathrm{C}$.

A chemical structure for prepared composite depends on the information get from XRF and TGA\& DTA thermograms about elemental analysis whose mass drop allows calculating an amount of $\mathrm{H}_{2} \mathrm{O}$ found in a matrix by an equation:

$$
18 \mathrm{n}=\frac{\mathrm{X}(\mathrm{M}+18 \mathrm{n})}{100}
$$

In which $\mathrm{X}$ is a mass drop percent of $\mathrm{H}_{2} \mathrm{O}$, n represents $\mathrm{H}_{2} \mathrm{O}$ mole number, \& $\mathrm{M}$ represents a compound molar mass without water molecules [1]. In which $\mathrm{X}$ is a mass drop percent of $\mathrm{H}_{2} \mathrm{O}$, n represents $\mathrm{H}_{2} \mathrm{O}$ mole number, \& $\mathrm{M}$ represents a compound molar mass without water molecules [1]. An X value for magnesium silicate was 8.2 $\%$. The molecular formula of magnesium silicate was calculated and indicated that $\mathrm{Mg}_{1.1} \mathrm{SiO}_{3.2} \cdot 1.1 \mathrm{H}_{2} \mathrm{O}$.

The relationship between impacts of different grain sizes on TL sensitivity (Figure 4) reveals that TL intensity reduced when the grain size enlarged so that reduction of collection efficiency of measured radiation, and the other way round. The grain size range of magnesium silicate is located between 53-106 with $\mathrm{SD}=0.005$.

The glow curve model of magnesium silicate samples is shown in Figure 5 with $1.5^{\circ} \mathrm{C} / \mathrm{s}$ heating rate at different irradiated low doses (0.5 Gy - 2 Gy). A strong main peak located around $230^{\circ} \mathrm{C}$. As the dose increased the peak location doesn't change, but the thermoluminescence response increases linearly. For a maximum point of peak height, a linear relationship with dose is noticed, which suppose uses this point for dose 
163

164 165

166

167

168

169

170

171

172

173

174

175

176

177

178

179

180

181

182

$$
\mu_{\mathrm{g}}=\frac{\delta}{\omega}=\left(\frac{\mathrm{T}_{2}-\mathrm{T}_{\mathrm{m}}}{\mathrm{T}_{2}-\mathrm{T}_{1}}\right)
$$

$183 \delta$ is selected as $\left(\delta=\mathrm{T}_{2}-\mathrm{T}_{\mathrm{m}}\right) \mathrm{c} \delta \&$ b $\delta$ have a values of $1.71 \& 0$, respectively. Where $184 \mathrm{~T}_{1} \& \mathrm{~T}_{2}$ are temperatures of a half-intensity centering low \& high-temperature peak 185 borders, respectively. $\mu_{\mathrm{g}}$ for $230^{\circ} \mathrm{C}$ thermal peak for Mgsi determined to be 0.51 , which 186 indicates that this peak follows a second-order reaction kinetics. When activation

187 energy $\mathrm{E}$ and kinetics order were determined, a frequency factor $\mathrm{S}$ can be estimated by 188 the next equation $[26,27]$ : 


$$
\frac{\beta_{\mathrm{E}}}{\mathrm{KT}_{\mathrm{m}}^{2}}=\mathrm{S}\left(1+(\mathrm{b}-1) \frac{2 \mathrm{KT}_{\mathrm{m}}}{\mathrm{E}}\right) \exp \left(-\frac{\mathrm{E}}{\mathrm{KT}_{\mathrm{m}}}\right)
$$

190 Assuming $B$ is a heating rate, the calculation of frequency factor $S$ is $1.11 \times 10^{7} \mathrm{~s}^{-1}$ 191 concerning the former traps filling next to the excitation and therefore on the dose responsible for excitation [28].

A process of sample preparation was the precipitation reaction at $25 \pm 1{ }^{\circ} \mathrm{C}$. An 195 arrangement of traps created using $\gamma$-radiation process may be changed by the alteration 196 for concentrations of substances i.e. concerning a radiation impacts in inorganic dosimetry, enhancement of concentrations leads to thermal activation energy increased. For all TL output, the studied concentration range was favorable.

In both Fig. 6 and Fig. 7, for glass doped within magnesium, different doses and 201 subsequent TL-response represented as an integral peak value and peak height. For low 202 doses, magnesium ions doped host material showed a TL-response in a linear 203 relationship. The straight line has a slope $=1$ from a glow peak temperature trap depth 204 205 E could be determined by equation (5):

$$
\mathrm{E}=\mathrm{C}\left(\frac{\mathrm{KT}_{\mathrm{m}}}{2}\right)-\mathrm{b}\left(2 \mathrm{KT}_{\mathrm{m}}\right)
$$

Where $\mathrm{T}_{\mathrm{m}}$ : temperature of a thermal peak, $\mathrm{K}$ : Boltzmann constant $\mathrm{T}_{\mathrm{m}}$ picked up as a high-temperature half-width $\left(\mathrm{T}_{2}-\mathrm{T}_{1}\right), \mathrm{C} \& \mathrm{~b}$ values are considered as constants of peak shape. In the case of the second-order equation, $C$ value: 2.54 and $b$ value: 1 . the trap depth [E] of the sample's principal peak arises at $230^{\circ} \mathrm{C}$ was determined as $1.18 \mathrm{eV}$. Densities of trapped carriers are represented by peak intensity and trap depth affecting recombination among holes and excited electrons. As seen in Fig. 6 and Fig. 7. The relative TL intensity for $\mathrm{MgSi}$ samples expressed in terms of different gamma doses, TL dose-response curve was observed in linear behavior inside dose range start with 0.5 Gray - 2 Gray. Suggesting that the suitability for radiotherapy applications. The 
straight-line slope value is 1.25 . From a dosimetric point of view, glow curves integral value under $230^{\circ} \mathrm{C}$ peaks is utilized to absorbed dose calculation The linear part expressed by equation $\mathrm{Y}=1.25 \mathrm{x}+\mathrm{b}$ where $\mathrm{Y}$ : represent TL-response in arbitrary units and $\mathrm{X}$ considered absorbed dose represented in the gray unit. The extrapolation to $\mathrm{Y}$ axis and equal: 360 , a: represent slope amount $=1.25$. The $\mathrm{TL}-$ dosimeter response can be calculated from this relationship and the absorbed dose can be also determined.

Determination of fading is the main trouble in the thermoluminescence (TL) tool found in dosimetric scope, looks like personnel, clinical dosimetry, and environmental dosimetry [24]. When the accumulated TL signal or trapped charges after irradiation exposed to leakage, this operation is called the thermal fading effect. Fig. 8, shows the integral value of TL-intensity after stored silicate material used for 90 days. The fading or leakage percent value equal to $9 \%$ regarding the composition of magnesium silicate itself. To verify the stabilization state process, the TL measurements were carried out after $30 \mathrm{~min}$ for each. This similar time interval after irradiation to remove the signal of lower temperature peak.

Not only trapping centers ionization can explain the fading process of $\mathrm{MgSi}$ but also it should be considered as the second operation in silicates which is the diffusion of oxygen. Concerning silicate materials energy dependence, prepare 5 groups as energy points. At every point at least has 6 TLDs, every group irradiate with a dose of $2 \mathrm{~Gy}$ at a particular fixed energy. TL-intensity as an integration value after irradiation of glassy materials with $2 \mathrm{~Gy}$ at different radiation energies (Figure 9), different energies of the silicate samples showed a fixed dose-response relationship at a certain dose which recommend remarkable behavior of energy-independent for these materials.

Table 3, shows dosimetric characteristics of thermoluminescence technique including a domain of doses, method of annealing, spectrum shape, dose information, readout technique, the sensitivity of the sample, physical forms for magnesium ions glass 
244 doped, trap depth activation energy found to be $1.18 \mathrm{eV}$ because of more heat is needed 245 to estimate the particular peak around $230{ }^{\circ} \mathrm{C}$ which is responsible for dosimetry. 246 Thermoluminescence response of therapeutic dose ranges from 0.5 gray - 2 Gray 247 against the transferred dose without approach saturation level gives a chance in the future to utilize this modified samples in a phantom for review dose distribution treatment planning. The experimental data revealed that the magnesium silicate affected quantitatively but not qualitatively by the radiation TL- response according to the irradiated doses variance resulted from different created trap centers.

\section{Conclusion:}

From previous results it may be deducted that;

Magnesium silicate was prepared by precipitation technique. The patterns of XRD show that magnesium silicate has a crystalline structure.

* Concerning doping oxides type similar created trap centers resulted in. So that the sensitivity and response of TL-radiation based on the magnesium silicate constitution quantitatively only. 


\section{Funding information}

274 Not applicable

\section{Conflicts of Interest}

276 The authors whose names are listed immediately below certify that they have

277 NO affiliations with or involvement in any organization or entity with any financial 278 interest (such as honoraria; educational grants; participation in speakers' bureaus; 279 membership, employment, consultancies, stock ownership, or other equity interest; and 280 expert testimony or patent-licensing arrangements), or non-financial interest (such as 281 personal or professional relationships, affiliations, knowledge or beliefs) in the subject 282 matter or materials discussed in this manuscript.

\section{Author contribution}

M.R. Abass: Data curation, writing - original draft review \& editing. H.M. Diab: experimental work \& editing. M.M. Abou-Mesalam: experimental work.

Availability of data and material

Yes

Compliance with ethical standards

290 Yes

\section{Consent to participate}

$292 \quad$ Yes

\section{Consent for publication}

$294 \quad$ Yes

\section{Acknowledgments}

This word has been supported by the Egyptian Atomic Energy Authority and 297 National Institute for Standards, Egypt. Great thanks to all members of the nuclear fuel technology department, Egyptian Atomic Energy Authority for supporting this work. 


\section{References}

300 1. Abou-Mesalam MM, Abass MR, Abdel-Wahab MA, et al (2016) Complex 301 doping of d-block elements cobalt, nickel and cadmium in magneso-silicate composite and its use in the treatment of aqueous waste. Desalination and Water Treatment 57:25757-25764

2. Ismail L, Khalili F, Orabi FMA (2020) Modification of Silica Nanoparticles with Cysteine or Methionine Amino Acids for the Removal of Uranium (VI) from Aqueous Solution. Silicon 1-15

3. Wakabayashi S, Takahashi S, Matsunami H, et al (2020) Evaluation of ${ }^{137} \mathrm{Cs}$ ageing by dynamics of ${ }^{137} \mathrm{Cs} /{ }^{133} \mathrm{Cs}$ ratio in Andosol paddy fields with/without potassium fertilizer application. Journal of Environmental Radioactivity 218:106252

4. Dubey N, Dubey V, Saji J, Kaur J (2020) Thermoluminescence glow curve analysis and trap parameters calculation of $\mathrm{UV}$-induced $\mathrm{La}_{2} \mathrm{Zr}_{2} \mathrm{O}_{7}$ phosphor doped with gadolinium. Journal of Materials Science: Materials in Electronics 31:1936-1944

5. Chialanza MR, Castiglioni J, Fornaro L (2012) Crystallization as a way for inducing thermoluminescence in a lead borate glass. Journal of Materials Science 47:2339-2344

6. Del Nery SM, Pontuschka WM, Isotani S, Rouse CG (1994) Luminescence quenching by iron in barium aluminoborate glasses. Physical Review B 49:3760

7. Pontuschka WM, Kanashiro LS, Courrol LC (2001) Luminescence mechanisms for borate glasses: the role of local structural units. Glass Physics and chemistry 27:37-47

8. Rao PN, Raju GN, Rao DK, Veeraiah N (2006) Optical absorption and thermoluminescence studies on $\mathrm{LiF}-\mathrm{Sb}_{2} \mathrm{O}_{3}-\mathrm{B}_{2} \mathrm{O}_{3}$ glasses doped with $\mathrm{Ni} 2+$ ions. Journal of luminescence 117:53-60

9. Marrale M, Longo A, Bartolotta A, et al (2013) Preliminary application of thermoluminescence and single aliquot regeneration method for dose reconstruction in soda lime glass. Nuclear Instruments and Methods in Physics Research Section B: Beam Interactions with Materials and Atoms 297:58-63

10. Dewangan P, Bisen DP, Brahme N, et al (2018) Studies on thermoluminescence properties of alkaline earth silicate phosphors. Journal of Alloys and Compounds 735:1383-1388

11. Kaur R, Bhatia V, Kumar D, et al (2019) Physical, structural, optical, and thermoluminescence behavior of $\mathrm{Dy}_{2} \mathrm{O}_{3}$ doped sodium magnesium borosilicate glasses. Results in Physics 12:827-839

12. Dewangan P, Bisen DP, Brahme N, et al (2019) Thermoluminescence glow curve for UV induced $\mathrm{Sr}_{3} \mathrm{MgSi}_{2} \mathrm{O}_{8}$ phosphor with its structural characterization. Journal of Materials Science: Materials in Electronics 30:771-777 
13. Dogan T, Akça S, Yüksel $\mathrm{M}$, et al (2019) Comparative studies on thermoluminescence characteristics of non-doped $\mathrm{Mg}_{2} \mathrm{SiO}_{4}$ prepared via a solidstate reaction technique and wet-chemical method: An unusual heating rate dependence. Journal of Alloys and Compounds 795:261-268

14. Mhareb MHA, Almessiere MA, Sayyed MI, Alajerami YSM (2019) Physical, structural, optical and photons attenuation attributes of lithium-magnesiumborate glasses: role of $\mathrm{Tm}_{2} \mathrm{O}_{3}$ doping. Optik 182:821-831

15. Divina R, Marimuthu K, Sayyed MI, et al (2019) Physical, structural, and radiation shielding properties of $\mathrm{B}_{2} \mathrm{O}_{3}-\mathrm{MgO}-\mathrm{K}_{2} \mathrm{O}-\mathrm{Sm}_{2} \mathrm{O}_{3}$ glass network modified with $\mathrm{TeO}_{2}$. Radiation Physics and Chemistry 160:75-82

16. Elkholy MM (2003) Thermoluminescence for rare-earths doped tellurite glasses. Materials chemistry and physics 77:321-330

17. Pagonis V, Mian S, Mellinger R, Chapman K (2009) Thermoluminescence kinetic study of binary lead-silicate glasses. Journal of Luminescence 129:570 577

18. Abou-Mesalam MM, Abass MR, Ibrahim AB, et al (2019) Tunable optical and dielectric properties of polymeric composite materials based on magnesosilicate. Bulletin of Materials Science 42:31

19. Ali IM, Kotp YH, El-Naggar IM (2010) Thermal stability, structural modifications, and ion exchange properties of magnesium silicate. Desalination 259:228-234

20. Al-Degs YS, El-Barghouthi MI, Issa AA, et al (2006) Sorption of Zn (II), Pb (II), and Co (II) using natural sorbents: equilibrium and kinetic studies. Water research 40:2645-2658

21. Madejová J (2003) FTIR techniques in clay mineral studies. Vibrational spectroscopy 31:1-10

22. Abou-Mesalam MM, El-Naggar IM (2008) Selectivity modification by ion memory of magneso-silicate and magnesium alumino-silicate as inorganic sorbents. Journal of hazardous materials 154:168-174

23. Hamoud MA, Allan KF, Sanad WA, et al (2014) Gamma irradiation-induced preparation of poly (acrylamide-itaconic acid)/zirconium hydrous oxide for removal of Cs-134 radionuclide and methylene blue. Journal of Radioanalytical and Nuclear Chemistry 302:169-178

24. Abou-Mesalam MM (2003) Sorption kinetics of copper, zinc, cadmium, and nickel ions on synthesized silico-antimonate ion exchanger. Colloids and Surfaces A: Physicochemical and Engineering Aspects 225:85-94. https://doi.org/10.1016/S0927-7757(03)00191-2

25. Chen R (1969) On the calculation of activation energies and frequency factors from glow curves. Journal of Applied Physics 40:570-585

26. Garlick GFJ, Gibson AF (1948) The electron trap mechanism of luminescence 
380 27. Rasheedy MS (1993) On the general-order kinetics of the thermoluminescence 381 glow peak. Journal of Physics: Condensed Matter 5:633

28. Furetta C, Kitis G, Brambilla A, et al (1999) Thermoluminescence 
Figures

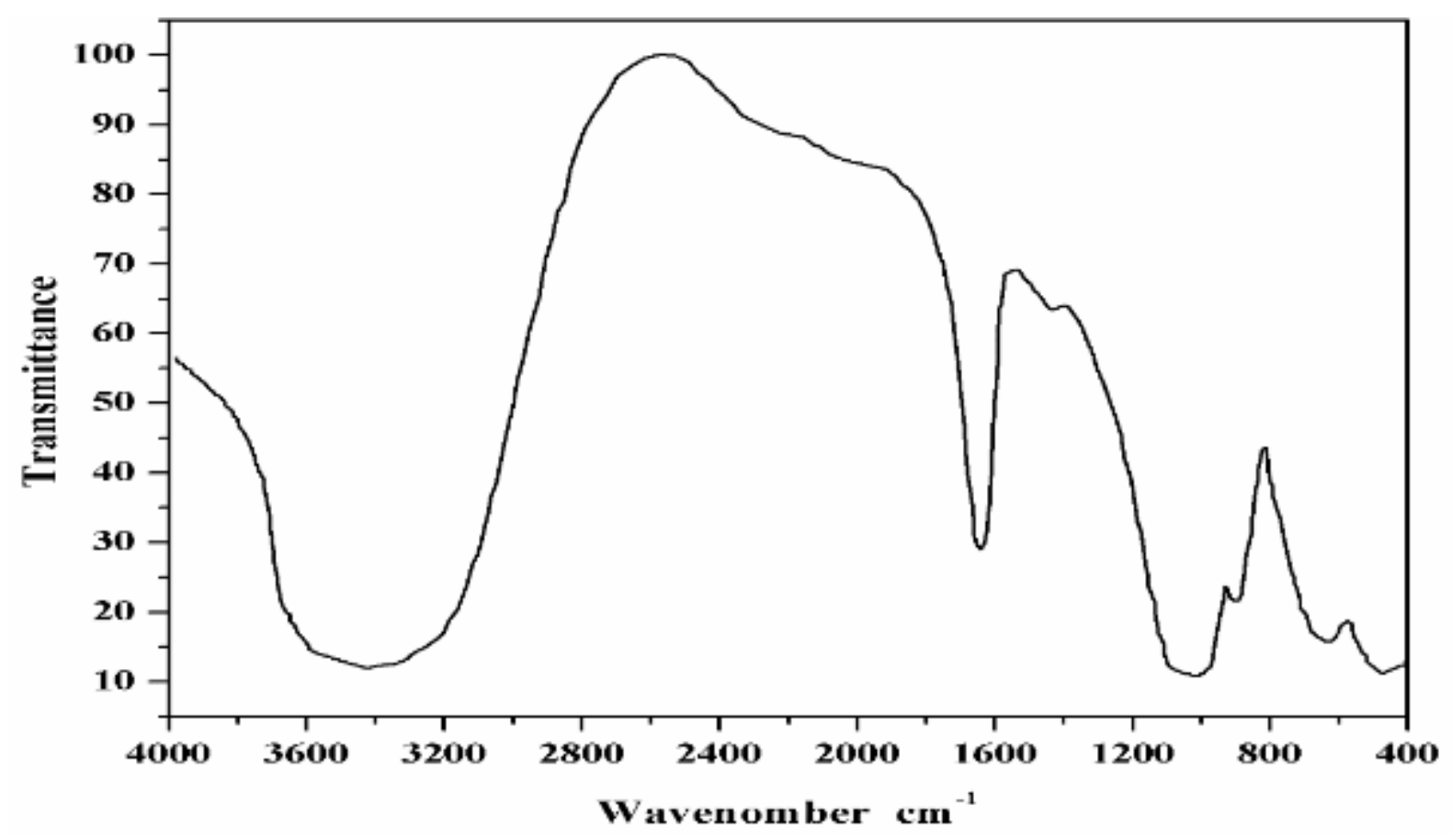

Figure 1

IR spectrum for magnesium silicate

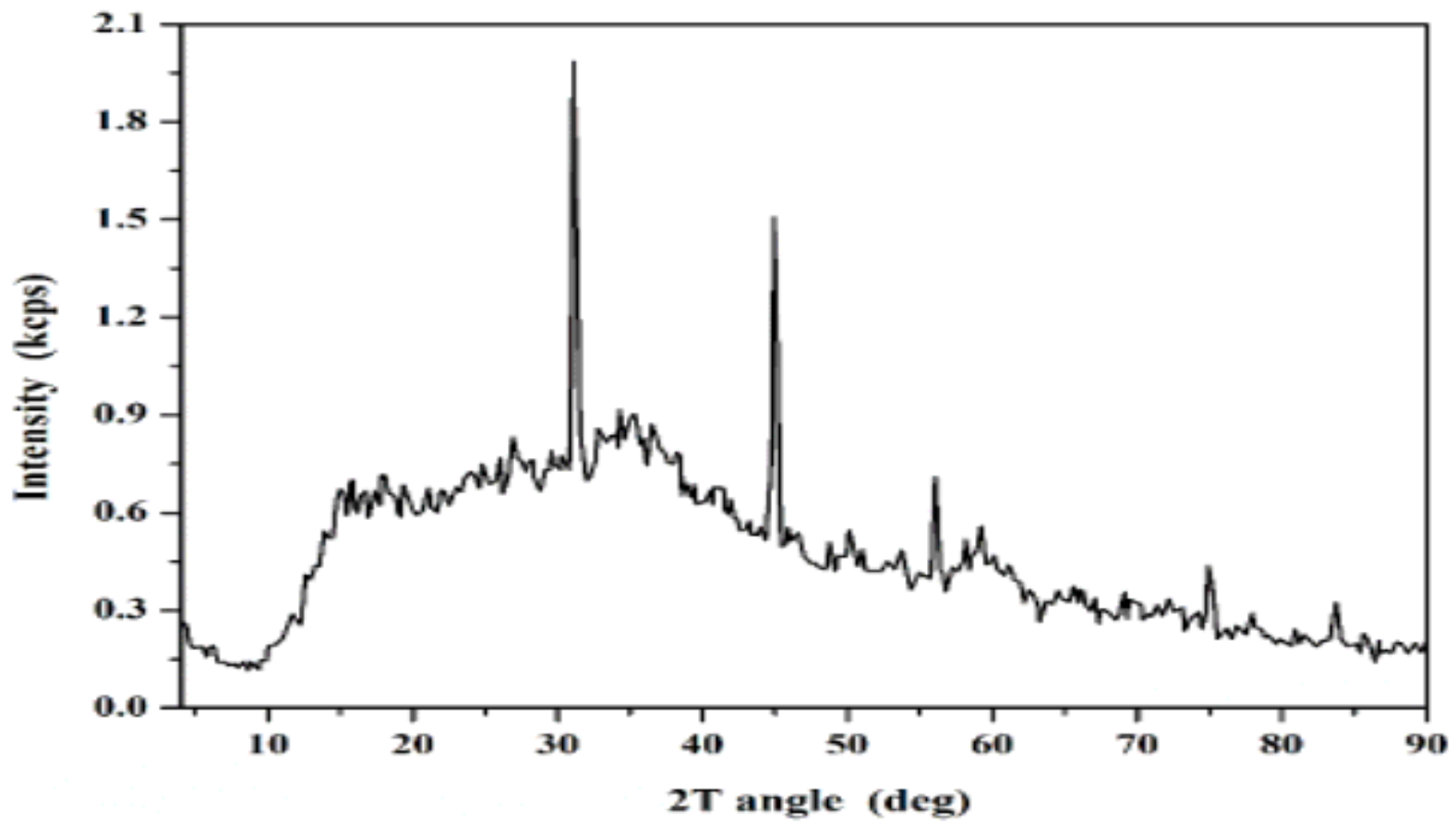

Figure 2

XRD for magnesium silicate 


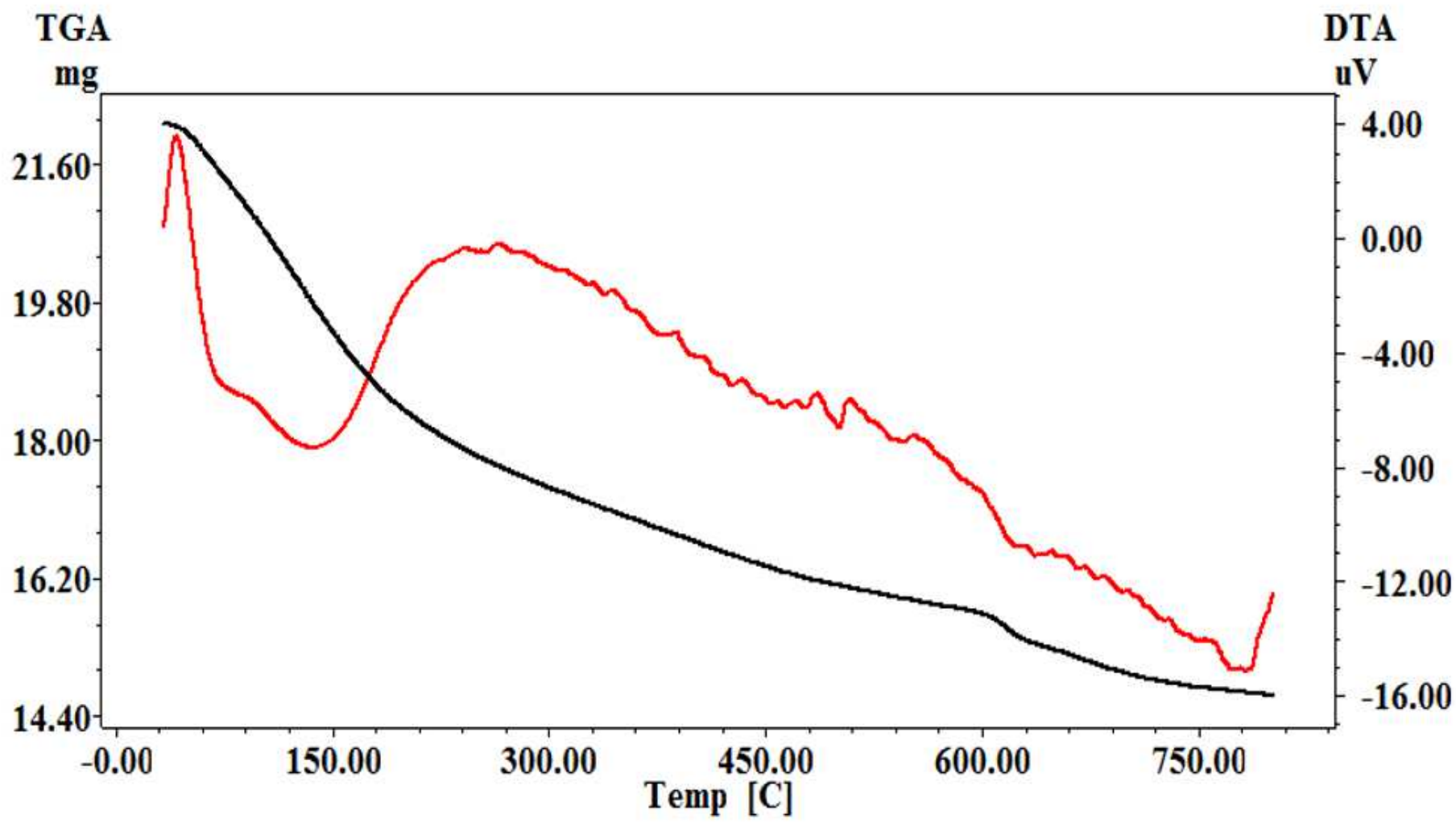

Figure 3

DTA\&TGA for magnesium silicate

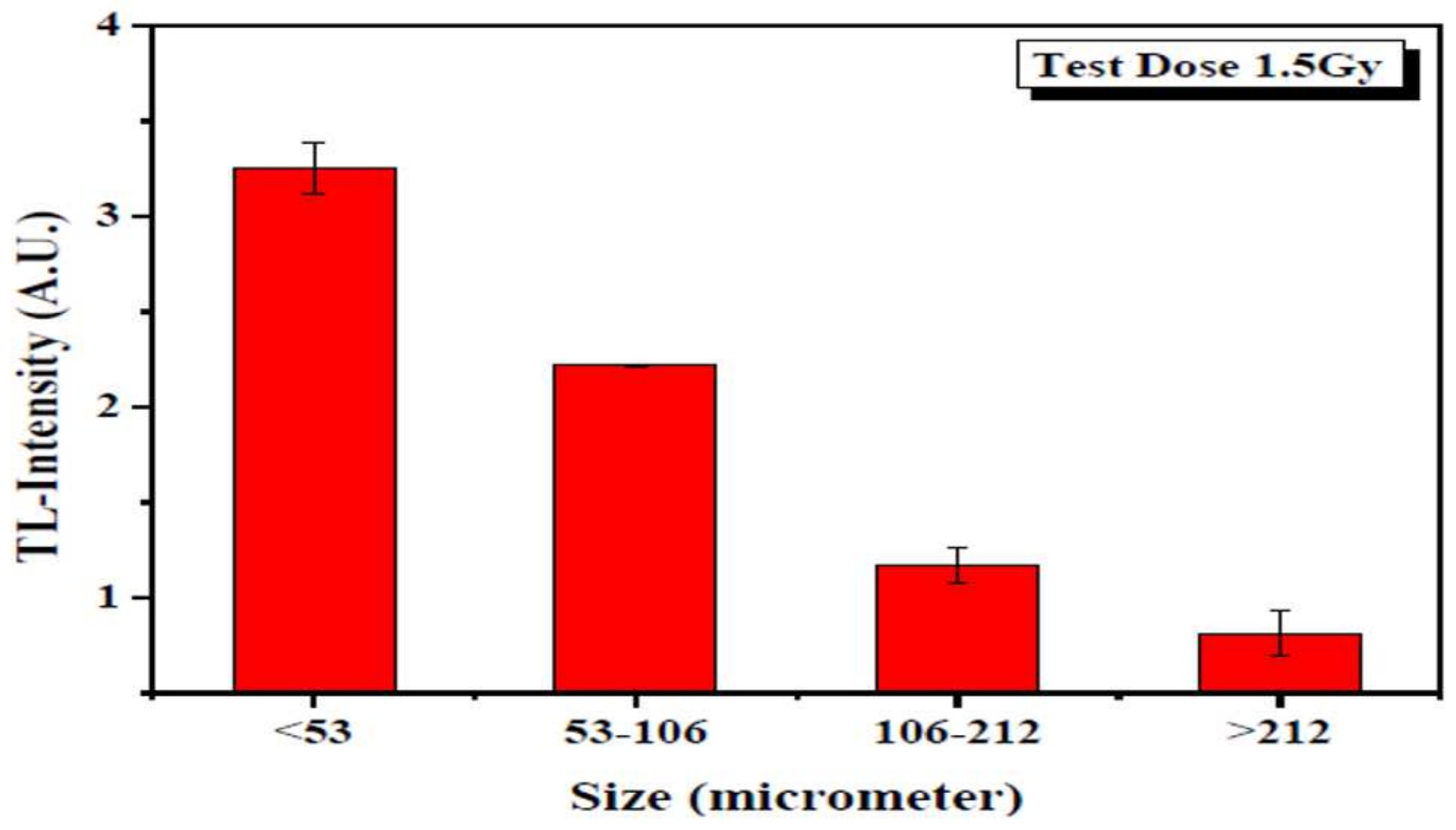

Figure 4 
The grain size effect on the TL-sensitivity. The error in the size range 53-106 is SD=0.0049.

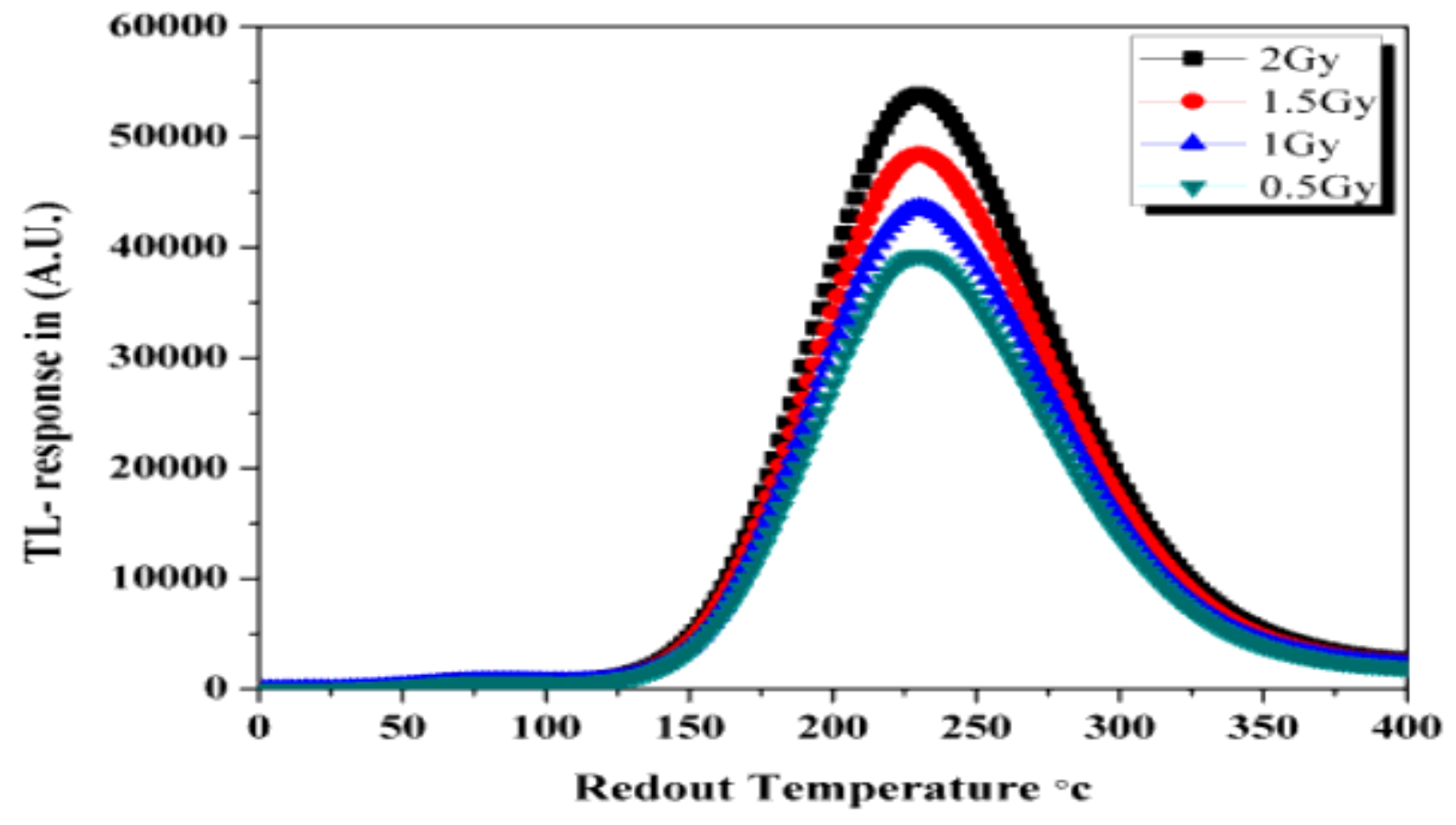

Figure 5

The different glow curves for different doses for magnesium silicate.

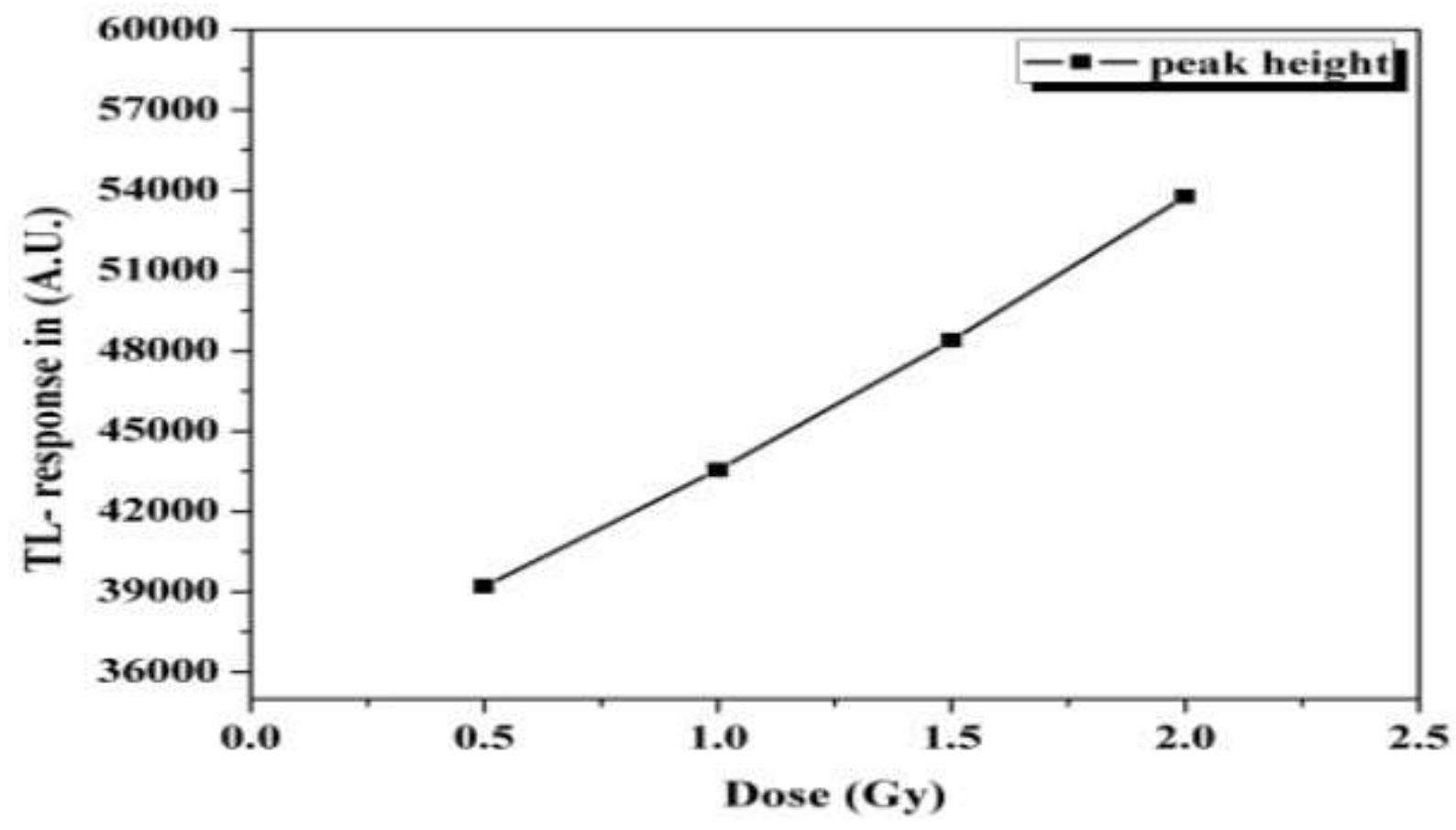

Figure 6

TL response vs. dose of magnesium silicate irradiated with 137Cs photons. TL response is represented by peak height from $0^{\circ} \mathrm{C}$ up to $360^{\circ} \mathrm{C}$. 


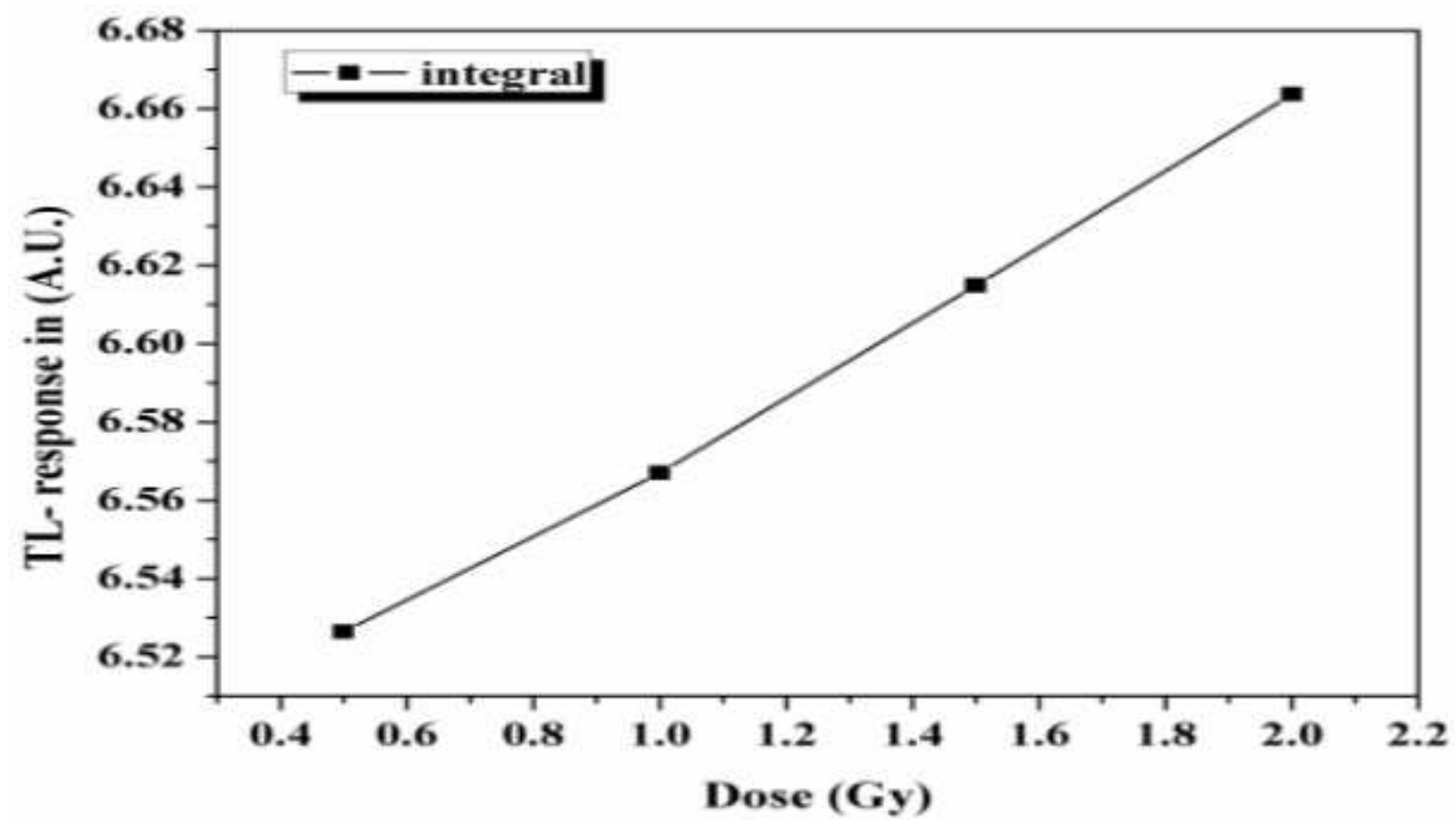

Figure 7

Dose against TL response of magnesium silicate irradiated with 137Cs photons. TL response is represented by an integral value from $0^{\circ} \mathrm{C}$ up to $360^{\circ} \mathrm{C}$.

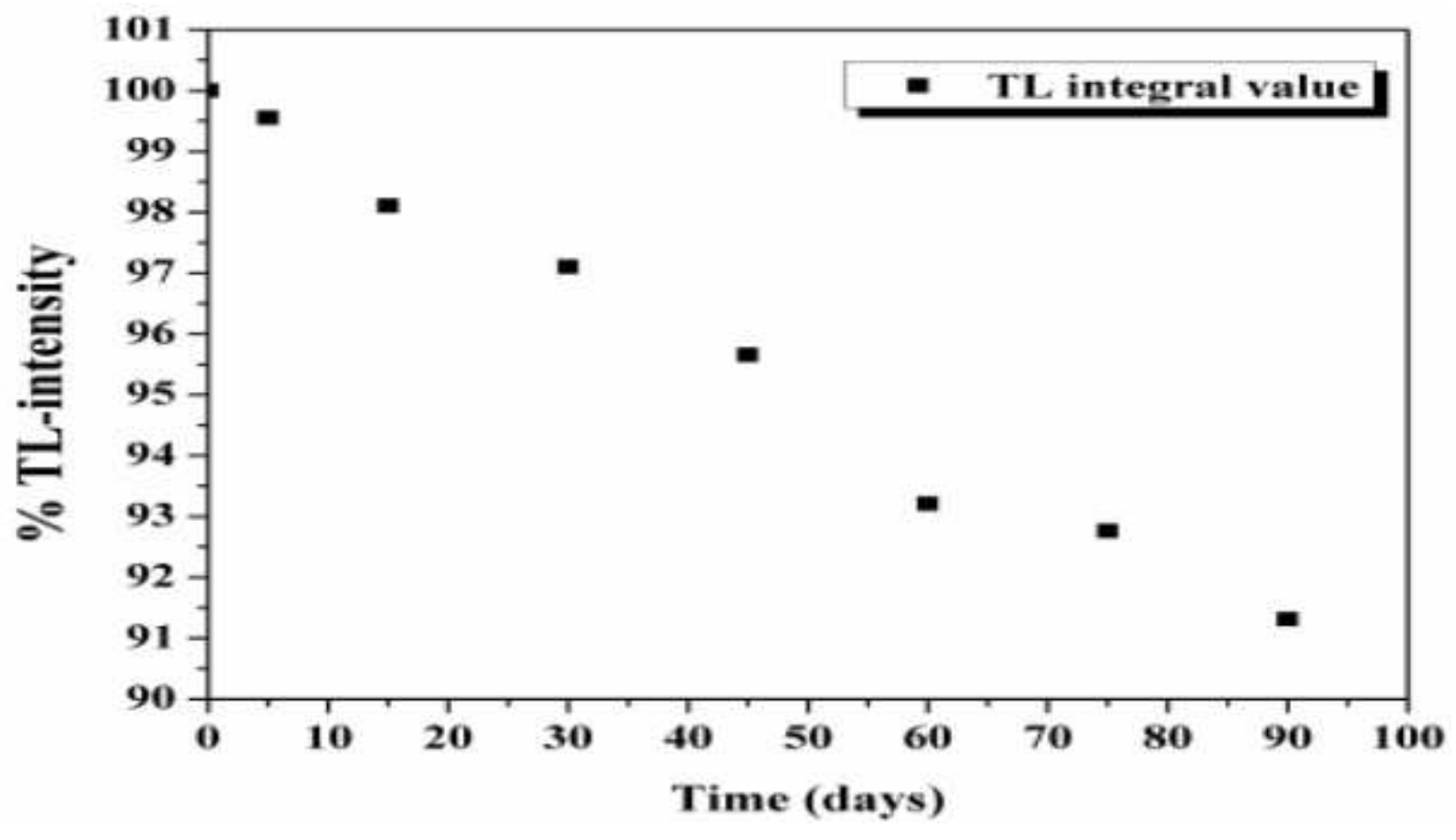

Figure 8

The fading process is represented by the TL-intensity of different dosimeters at room temperature. 


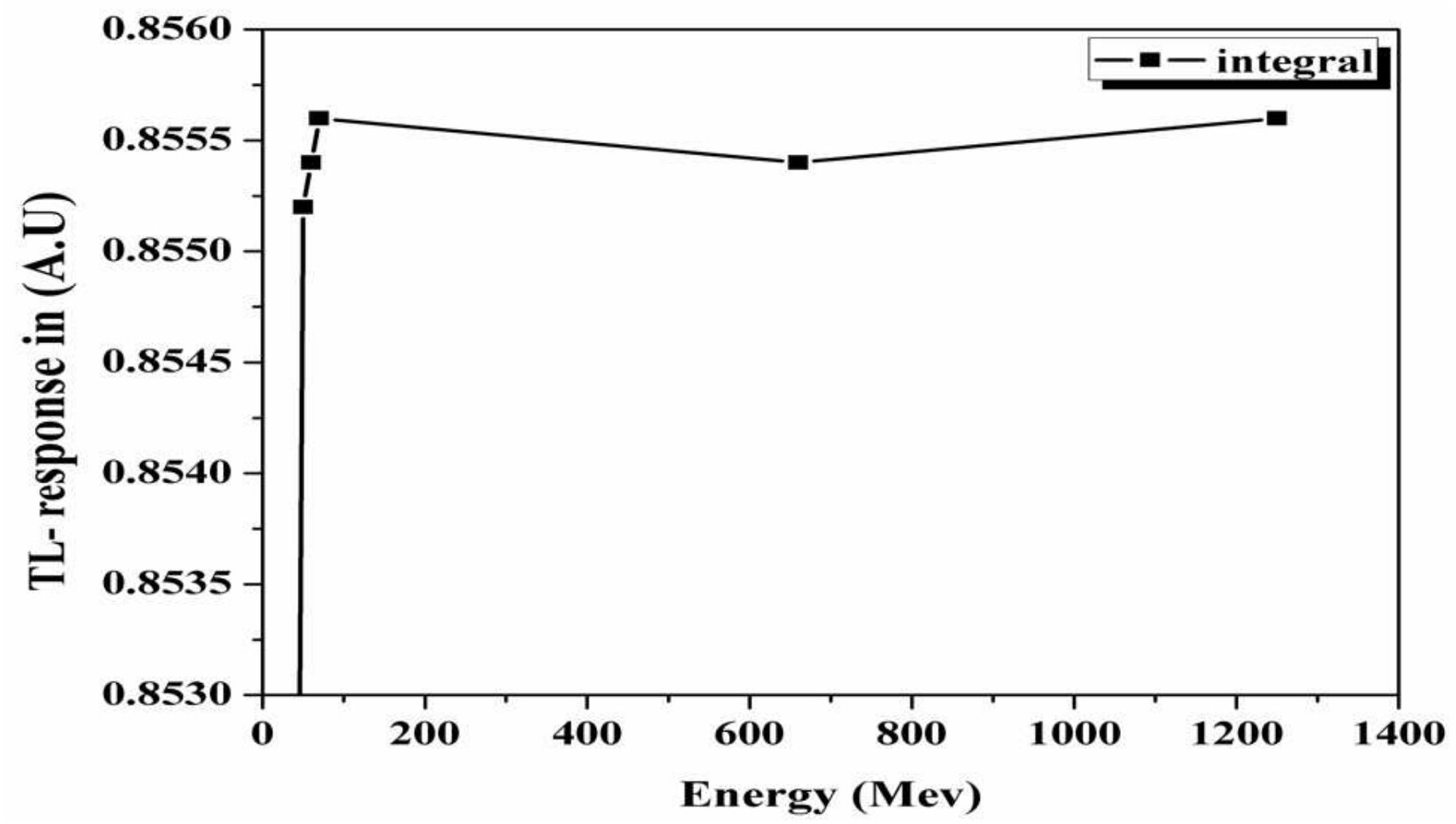

Figure 9

The energy-dependent process is represented by the TL-intensity of different dosimeters at room temperature.

\section{Supplementary Files}

This is a list of supplementary files associated with this preprint. Click to download.

- Scheme1.png

- Highlights.docx 